\title{
WESTERLUND (David), SVANBERG (Ingvar), éds., Islam Outside the Arab World
}

Richmond, Curzon Press, 1999, 476 p. (bibliogr., index)

\section{Christian Décobert}

\section{(2) OpenEdition}

\section{Journals}

Édition électronique

URL : http://journals.openedition.org/assr/20491

DOI : 10.4000/assr.20491

ISSN : $1777-5825$

Éditeur

Éditions de l'EHESS

Édition imprimée

Date de publication : 31 décembre 2000

Pagination : 175-176

ISBN : 2-222-96698-1

ISSN : 0335-5985

Référence électronique

Christian Décobert, "WESTERLUND (David), SVANBERG (Ingvar), éds., Islam Outside the Arab World», Archives de sciences sociales des religions [En ligne], 112 | octobre-décembre 2000, document 112.113 mis en ligne le 19 août 2009, consulté le 21 septembre 2020. URL : http://journals.openedition.org/ assr/20491 ; DOI : https://doi.org/10.4000/assr.20491

Ce document a été généré automatiquement le 21 septembre 2020.

(c) Archives de sciences sociales des religions 


\section{WESTERLUND (David), SVANBERG (Ingvar), éds., Islam Outside the Arab World}

Richmond, Curzon Press, 1999, 476 p. (bibliogr., index)

\section{Christian Décobert}

\section{RÉFÉRENCE}

WESTERLUND (David), SVANBERG (Ingvar), éds., Islam Outside the Arab World,Richmond, Curzon Press, 1999, 476 p. (bibliogr., index)

1 Cet ouvrage collectif part d'un constat certes connu, maintes fois signalé dans les travaux d'ensemble sur l'islam mais qui n'a guère eu de valeur heuristique pour une construction de l'objet religieux : $85 \%$ des musulmans vivent hors du monde arabe. Autrement dit, l'islam périphérique est infiniment plus massif qu'un islam central sur lequel l'intérêt s'est longuement concentré et à partir duquel une figure de l'ensemble s'est imposée. Une introduction historique à l'ouvrage rappelle d'ailleurs très utilement que cet islam dit périphérique n'est pas toujours, loin s'en faut, d'implantation récente. En Asie continentale ou en Asie du Sud-Est, par exemple, ses strates historiques sont profondes et constitutives des complexes sédimentaires locaux: l'islam ne saurait y être pris comme hétéronome, seulement importé, comme un adstrat.

2 L'ouvrage se veut introductif, il a pour seule ambition de présenter brièvement ces pays où il $\mathrm{y}$ a des musulmans, que ceux-ci vivent en masses dominantes ou en minorités tolérées. De la Somalie aux Caraïbes, de la Chine à la Suède ou à la Nouvelle Zélande, chaque pays ou groupe de pays proches fait l'objet d'un article. C'est-à-dire que sont rappelées brièvement les conditions historiques, anciennes ou récentes, d'existence de communautés musulmanes, et que sont évoqués leur statut, le mode de leur évolution, en bref, leur situation présente. Une bibliographie «de base» est présentée et rapidement commentée - les sondages que nous avons pratiqués montrent que les 
bibliographies sont suffisantes dans la mesure où les ouvrages mentionnés ont euxmêmes des bibliographies permettant d'appréhender véritablement ce qui s'est écrit et dit sur les musulmans des pays concernés. Il est bien évident que les notices sont très inégales selon que l'on parlera du monde irano-afghan ou de Trinidad et Tobago. Les quelque vingt-cinq pages consacrées à l'Iran, Afghanistan et Tajikistan s'apparentent plus à un article encyclopédique qu'à une notice.

3 Mais c'est précisément l'un des intérêts de l'ouvrage que de faire se côtoyer des articles de développements très différents pour des objets eux-mêmes très divers. Car ce n'est pas seulement la diversité des situations et des modes de vie qui se dégage de ce côtoiement, c'est également l'existence saisissante de traits communs. Un tel côtoiement fait notamment ressortir un fait massif dont on commence seulement à parler tant il a paru aveuglant : la dominance, au sens qu'un Maurice Godelier a donné à ce mot, d'un islam soufi. Bien plus que l'islamisme, le soufisme - une religiosité mystico-contemplative extramondaine (avec ses variantes, ses attaches multiples, ses procédures variées et plus ou moins exclusives d'intégration communautaire) - semble s'imposer comme mode privilégié de négociation de ce qu'on appellera la modernité religieuse (privatisation du croire, sécularisation de la pratique sociale, etc.). D'un article à l'autre, ce thème revient, ce ne sont pas les éditeurs qui l'ont imposé mais l'honnête description de ce qui se passe.

Cet ouvrage se veut modeste, il a été conçu comme une introduction à un islam vivant, voire tentaculaire. En fait, il est plus que cela, il est une vraie entrée en matière - dans la matière opaque de l'islam d'aujourd'hui. 